\title{
Estudos
}

\section{A Imprensa Periódica Especializada e a Pesquisa Histórica: Estudos sobre o Boletim de Educação Pública e a Revista Brasileira de Estudos Pedagógicos}

\section{Diana Gonçalves Vidal}

Faculdades Padre Anchieta (Jundiaí-SP)

Marilena Jorge Guedes de Camargo

Universidade Estadual Paulista Júlio de Mesquita Filho (UNESP-Rio Claro)

O artigo trata de dois estudos de revistas especializadas em educaçãoBoletim de Educação Pública e Revista Brasileira de Estudos Pedagógicos, na expectativa de que o contato inicial com estes periódicos acorra o pesquisador em História da Educação Brasileira, dando-lhe índices para seu trabalho. Na análise do Boletim de Educação Pública, privilegiou-se a sistematização de informações sobre o ciclo de vida, situando a revista no seu momento histórico e procurando perceber a publicação dentro das injunções políticas que lhe deram origem. Com respeito à Revista Brasileira de Estudos Pedagógicos, o enfoque incidiu sobre dois movimentos: um, técnico e burocrático, ligado diretamente ao programa do Instituto Nacional de Estudos Pedagógicos (INEP); e outro, teórico, refletindo as idéias dos autores da revista a observação dos fatos educacionais, exame dos princípios e análise de questõe de aplicação.

\section{Introdução}

Uma das dificuldades em realizar pesquisas, no Brasil, é a dispersão documental. Despendemos um tempo considerável tentando reunir os documentos 
necessários para a abordagem de nosso objeto - muitas vezes, refazendo os passos de outros pesquisadores. Talvez viessem a auxiliar o trabalho de campo algumas obras de referência, por mínimas que fossem. Essa foi a nossa intenção. Expomos, neste artigo, dois estudos sobre periódicos especializados em educação: o Boletim de Educação Pública, informando sobre seu ciclo de vida, e aRevistaBrasileira de Estudos Pedagógicos, abordando seus primeiros movimentos e direções; na expectativa de que o contato inicial com estas revistas acorra o pesquisador em História da Educação, dando-lhe índices para seu trabalho ${ }^{1}$.

O interesse em se estudar periódicos para a realização de análises históricas reside na possibilidade da leitura de manifestações contemporâneas aos acontecimentos. Desta maneira, realizamos uma aproximação do momento de estudo não pela fala de historiadores da educação, mas pelos discursos emitidos na época. Em lugar do grande quadro explicativo da História, da grande síntese que para ser efetuada desconhece detalhes e matizes, lidamos com a pluralidade: as diversas falas colorem a compreensão do período e indicam lutas diferenciadas, muitas vezes irrecuperáveis no discurso homogêneo do historiador de grandes quadros, fazendo-nos recuperar vieses que ficaram perdidos nas análises historiográficas posteriores. Tanto o discurso das grandes análises, quanto a fala dos agentes deslocada no tempo, por exemplo a apreciação de um educador sobre sua atuação passada, ocultam elementos que, na época da publicação das revistas, eram preocupações correntes, e depois foram esquecidos, obliterados por outras questões.

Esses fatos discursivos que compunham o universo da fala no tempo podem dimensionar melhor os debates, fazendo-nos perceber cada época na sua feição única e não como parte de um enorme processo histórico que arrola causas e consequências. O significado de cada época, buscado nas referências do momento e, não, na interpretação a posteriori, pode redimensionar nossa percepção do

\footnotetext{
${ }^{1}$ Os dois estudos foram compostos a partir das atividades realizadas em um curso ministrado pela professora Denice Bárbara Catani, no programa de pós-graduação da Faculdade de Educação da USP. O primeiro, sobre o Boletim de Educação Pública, é de autoria da professora Diana Gonçalves Vidal, e o segundo, sobre a Revista Brasileira de Estudos Pedagógicos, é de autoria da professora Marilena Aparecida Jorge Guedes de Camargo.
} 
período, permitindo-nos vislumbrar lutas e inquietudes numa paisagem que considerávamos harmônica.

\section{O Boletim de Educação Pública: informações sobre o seu ciclo de vida}

Entre as instituições auxiliares de ensino criadas pela reforma Fernando de Azevedo, no Distrito Federal, figurava o Boletim de Educação Pública, regulamentado pelos Decretos n ${ }^{\circ}$ s 3.281, de 23 de janeiro, e 2.940, de 22 de novembro de 1928.

Merece destaque o título. Apesar de ter sido uma publicação da Diretoria de Instrução, foi denominado Boletim de Educação Pública. A historiografia educacional identifica nos anos 20 e 30, principalmente, a difusão, no Brasil, de um ideário que ficou conhecido como escolanovista. Dentre os partícipes da concepção nova estavam Fernando de Azevedo e Anísio Teixeira. No plano do discurso, a Escola Nova realçava a necessidade da formação integral da criança: personalidade, hábitos, moral e conhecimento. A escola, concebida como local privilegiado de produção do indivíduo, deveria caber a tarefa de the desenvolver as potencialidades, despertando-o para a vida social. A mera erudição, reconhecida pelos representantes do pensamento novo, como objetivo da escola tradicional — à qual se contrapunham — ligava-se intimamente, segundo suas palavras, ao verbo instruir. Educar, entretanto, era compreender a criança na sua complexidade física e psicológica, adequando o ensino aos imperativos do desenvolvimento infantil. O Boletim, assim, marcava, já no título, a diferença entre a atuação da Diretoria instalada em 1927 e suas antecessoras, sendo índice dos novos rumos da administração pública no Distrito Federal.

Circulou durante os anos de 1930 e de 1932 a 1935, período coincidente com as atuações de Fernando de Azevedo (1927-1930) e Anísio Teixeira (19311935) à frente da Diretoria Geral de Instrução Pública do Distrito Federal ${ }^{2}$. Foram editados ao todo dezoito números, sendo quatro, trimestralmente, no

\footnotetext{
${ }^{2}$ Com a reforma de Anísio Teixeira, em 1932, passou a ser denominada Diretoria Geral do Departamento de Educação do Distrito Federal.
} 
ano de 1930; e quatorze, divididos em sete volumes ${ }^{3}$, semestralmente, no anos seguintes. A interrupção no ano de 1931, uma ligeira mudança no conteúdo e disposição das seções no período do Governo Vargas e o reinício da numeração do periódico a partir de 1932 fizeram-me identificar duas fases de publicação: a primeira, sob a administração de Azevedo, e a segunda, sob administração de Teixeira. Adiante elucido propriamente estas diferenças que por ora deixo somente indicadas. O caráter mesmo do Boletim, entretanto, não se alterou, permanecendo fiel aos princípios que the deram origem, como afirma a "Nota explicativa", introdutória ao primeiro número do que, de agora em diante, denomino segunda fase.

Os volumes não vinham acompanhados de editoriais, à exceção dos primeiros números das distintas fases, que foram iniciados com "Introdução" e "Nota explicativa", respectivamente. Esses textos, não assinados, tinham por função caracterizar, em linhas gerais, o Boletim, indicando público-alvo, objetivos e diretrizes. Por isso, sirvo-me desses "prefácios" para, a princípio, revelar a intenção dos reformadores ao compor e editar o periódico.

De acordo com a "Introdução", o Boletim destinava-se "...a divulgar trabalhos técnicos originais, de pesquisa, orientação e cultura, conferências do curso de férias, na íntegra ou em resumo, e de modo geral quaisquer artigos e trabalhos técnicos originais e de real valor". Não seria um boletim informativo de atos oficiais ou propagador de temas ou exercícios para uso docente, mas deveria estudar "...os grandes problemas que a reforma de ensino pôs em foco" (v. 1, n. 1, p.5,jan./mar. 1930). Ou seja, propunhase a difundir o pensamento escolanovista aos professores cariocas, de maneira a torná-los cada vez mais aptos a levar a efeito os dispositivos da

\footnotetext{
${ }^{3}$ O Boletim não fazia distinção entre volumes e números. Como. na segunda fase, os números foram agrupados dois a dois. chamei, aqui, a este conjunto, de volume. No entanto, no restante do texto usarei as palavras número e volume como sinônimos. 4 "Ressurge resguardando fidelidade aos propósitos que tomaram imperiosa a sua criação, e até ao feitio material com que surgiu, para ser porta-voz por excelência do pensamento dirigente do grande sistema escolar do Rio de Janeiro, DF, para dar contas do que ele vai projetando ou podendo realizar e para divulgar, como tanto convém ao Brasil e aos Brasileiros, o que se passa no mundo em matéria de Educação, quer na esfera do pensamento e da doutrina, quer no campo da ação e das realizações, das novas experiências e ensaios, novos métodos, novos processos e novas técnicas." ("Nota explicativa", v.2. n.1/2, jan./jun. 1932). Todas as citações referentes a matérias veiculadas no Boletim de Educação Pública serão indicadas, resumidamente, apenas especificando ano, número e data do exemplar, como efetuado acima.
} 
reforma. A "Nota explicativa" reforçava esta determinação, afirmando que o Boletim deveria "...divulgar (...) o que passa no mundo em matéria de Educação, quer na esfera do pensamento e da doutrina, quer no campo da ação e das realizações..." (v.2, n.1/2, p.5, jan./jun.1932).

Ao Boletim era imputado um papel formador, condizente com os discursos dos educadores escolanovistas, que acreditavam ter a missão de renovar a educação nacional, crivada pelo pensamento, por eles denominado, tradicional. Se, por um lado, exercia tal tarefa pedagógica, e por isso poder-se-ia afirmar que sua criação seguia tão-somente imperativos técnicos — aliás, refazendo a fala da neutralidade da ação política dos reformadores —, por outro, a disseminação das idéias novas e das realizações da administração pública faziam parte da obra de cooptação docente que empreendeu, principalmente, Fernando de Azevedo ${ }^{5}$ : uma tarefa eminentemente política.

Ex-jornalista de $O$ Estado de São Paulo, Azevedo compreendia a importância da propaganda para a produção de uma opinião pública que oferecesse suporte ao trabalho em desenvolvimento na Diretoria Geral de Instrução Pública ${ }^{6}$. Desde sua nomeação para o cargo de diretor geral, este professor mineiro, radicado em São Paulo, não havia feito concessões à população ou aos políticos locais ao apresentar suas idéias. Em 1927, invadira os lares cariocas contabilizando crianças em idade escolar. Em 1928, pressionara o Conselho Municipal impondo a aprovação da Reforma sem aceitar que lhe fossem impostos cortes. Nesse mesmo período, demitira todos os professores contratados irregularmente, por indicação política, que não haviam prestado concurso.

Muito seguro da relevância das medidas que tomava para regulamentar a educação no Distrito Federal, fato que podemos atestar relendo as obras

\footnotetext{
${ }^{5}$ Corroborando esta tese, em seus artigos, encontramos sempre referências elogiosas a mulheres e a professoras (v. 1. n. 1, p.23, jan./mar. 1930; v.1, n.2, p.179, abr./jun. 1930; v.1, n.4, p.496, out/dez. 1930).

${ }^{6}$ Já no primeiro número do Boletim, nas falas de Frota Pessoa e Jonalhas Serrano, há comentários sobre as manifestações contrárias à Reforma, em particular provenientes do Conselho Municipal, que qualificou o projeto como utópico, dispendioso e inadequado ao meio social (v.1., n.1,p.82e 109). Fernando de Azevedo, em Novos Caminhos, Novos Fins, ressalta a importância da propaganda na sua gestão: "A rapidez da transformação, a audácia das inovações introduzidas e a necessidade de vencer as resistências impunham, sobre uma direção uniforme, vigilante e onipresente (...) todo o sistema de propaganda e popularização " (Obras completas, v.7, p.23).
} 
escritas posteriormente a sua administração carioca, onde reiterava várias vezes a importância da Reforma para a transformação da História da Educação Brasileira ${ }^{7}$, Fernando atuava com intransigência na Diretoria. Cultivava inimizades.

Um exemplo dessa determinação administrativa foi a celeuma levantada entre o Conselho Municipal e a Diretoria Geral da Instrução Pública a respeito da aprovação do projeto da Reforma. Desde sua posse, Fernando iniciara uma campanha contra o excesso de contratações para os cargos do sistema escolar. No discurso, de posse, proferido em 17 de janeiro de $1927^{8}$, Azevedo comentou o fato de que uma verdadeira multidão de professores constava da folha de pagamento da Escola Normal. Em dezembro desse mesmo ano, em almoço promovido pelo Rotary Club do Rio de Janeiro, atacou o corpo docente da Escola, dizendo: "Este ginásio para moças, pomposamente batizado de Escola Normal, tem hoje 187 professores, todos vitalícios dos quais apenas cerca de $40 \mathrm{em}$ atividade. Os outros 147 são dedicados pensionistas do Estado que despende para mantelos em completa inatividade em cargos sem funções, recebidos de mãos beijadas, perto de mil contos...". Comparando a Escola Normal ao Colégio Pedro II, afirmou que o custo médio de uma normalista era de 2 contos e 200 mil réis, enquanto o aluno do Pedro II custava ao Estado apenas 1 conto de réis.

Parte das contratações públicas seguiam as indicações feitas por membros do Conselho Municipal. Assim, ao atacar o corpo docente da Escola Normal, visava atingir os políticos do Distrito Federal, instituindo limites entre sua atuação e a performance da Diretoria ${ }^{9} .0$ próprio texto da Reforma determinava como única

\footnotetext{
${ }^{7}$ Ver especialmente Azevedo, em Vitória sobre as Forças de Dissolução (Obras completas, v.7, p. 191), escrito por ocasião do décimo aniversário da Reforma, onde citando Frota Pessoa, afirma: "com o decreto da reforma 'se colocou subitamente o Brasil na vanguarda do movimento universal pela renovação da escola, e se marcou, na história do Brasil, uma etapa análoga à da independência e à da abolição'". E, também, neste mesmo volume, p. 143, o discurso que seria pronunciado na inauguração do novo prédio da Escola Normal, em outubro de 1930, onde dizia: "Eu não tinha senão uma idÉia: inaugurar uma nova era de educação no Brasil".

${ }^{8}$ Alguns discursos proferidos por Fernando de Azevedo, enquanto diretor geral, foram compilados e publicados pela Editora Melhoramentos, em Obras Completas, especialmente volume VII, denominado Novos Caminhos, Novos Fins, todo dedicado ao período de sua administração no Distrito Federal. Neste volume encontraremos, ainda, compilados os artigos que publicou, no ano de 1930, no Boletim de Educação Pública.

' "A disposição, em que me mantive, de redimir a educação pública do ignóbil cativeiro político a que a reduziram, cerca de 40 anos de submissão às injunções partidárias, tinha de forçosamente provocar uma hostilidade irredutível entre meu ponto de vista técnico (...) e o ponto de vista estreito das preocupações e interesses políticos." (Azevedo, Obras completas, v.7, p.23-24).
} 
maneira legítima de ascensão a um cargo da área educacional o concurso público. Por fim, para adequar o quadro à função docente, promoveu demissões dos professores cujo processo de contratação havia seguido os ditames do conchavo político.

Tal disputa com os políticos locais e os professores rendeu-lhe várias críticas, assinadas ou não, veiculadas pela imprensa, e foi uma das bases dos inquéritos realizados sobre sua administração, após a posse do Governo Revolucionário, em novembro de 1930, promovidos pelos dois Diretores Gerais da Instrução Pública que the sucederam, ambos seus opositores ferrenhos. O primeiro deles, Osvaldo Orico, professor da Escola Normal, à época, havia se manifestado contrário às demissões de seus pares, que considerou como arbitrárias, ilegais e violentas ${ }^{10}$.

Ao Boletim, então, foi imputada a tarefa de veicular o pensamento reformador e, principalmente, de convencer o professorado carioca da necessidade de consecução da Reforma e da conveniência dos meios por ela utilizados. No entanto, pensar que as fronteiras estabelecidas para a circulação do Boletim se restringiam ao Distrito Federal não corresponde aos anseios expressos nos "prefácios". Continuando a ler a "Introdução", percebemos que o público-alvo a que se destinava a revista não se resumia ao corpo docente carioca. O Boletim projetava-se para todo o Brasil, os Estados Unidos da América e a Europa, oferecendo-se em permuta com as publicações de congêneres nacionais e estrangeiras. Esse desejo de intercâmbio nacional e internacional estava reiterado na "Nota explicativa".

Tal perspectiva correspondia a uma das características do movimento escolanovista - e ao próprio momento histórico: o cosmopolitismo. Após a Primeira Grande Guerra, o mundo reduzira-se. Os conflitos, antes locais, assumiam escala mundial. A radiodifusão contribuía para essa percepção diminuta das distâncias. As notícias espalhavam-se com grande rapidez e havia interesse em conhecer fatos de todos os países. A leitura do Boletim

\footnotetext{
${ }^{10}$ Lemme, 1988, v.2, p.74-75. O professor Alfredo B. da Silveira (1954, p.45), assim se expressa a respeito das demissões: "... mas, o despotismo n5o é eterno c ao Poder Divino não escaparão os violadores dos direitos dos semelhantes. O movimento vitorioso de 24 de outubro de 1930 deu substituto ao Prefeito Antônio Prado Júnior".
} 
nos mostra que a troca nacional e internacional de correspondência" era estimulada, que as viagens de professores aos Estados Unidos para frequentar cursos de aperfeiçoamento eram constantes ${ }^{12}$ e que a recepção de periódicos estrangeiros era contemporânea quase à sua publicação ${ }^{13}$.

Imbuído desse ideal cosmopolita, ciente do valor do periódico para a formação intelectual do professorado e para a divulgação dos fatos de sua Reforma, como exposto, Anísio deu prosseguimento à publicação. No entanto, um olhar mesmo descuidado percebe no Boletim, nesta segunda fase, um caráter diferenciado. A edição tornou-se semestral para "melhor cumprir prazos" ("Nota explicativa", v.2, a 1/2,1932). A regularidade, tanto do número de páginas, quanto da quantidade de artigos e do formato das seções, característica da fase anterior ${ }^{14}$, não pôde ser reencontrada. O Boletim, entretanto, cresceu, pois cada número vinha acompanhado de uma separata, escrita por Anísio Teixeira: uma análise semestral da administração. Os volumes variavam de 200 a 300 páginas e continham informações detalhadas do que se estava realizando no sistema escolar municipal. Continuava a ser o porta-voz oficial da, então, Diretoria Geral do Departamento de Educação do Distrito Federal, assumindo um caráter mais informativo que formativo $^{15}$.

O Boletim, nas suas duas fases, era composto de quatro seções: artigos, "Factos e iniciativas", "Através das Revistas" e "Bibliographia". A primeira seção apresentava trabalhos diversos, geralmente relacionados ao momento histórico

\footnotetext{
" São diversas as notícias de intercâmbio e várias as propostas de realizar um correio interescolar. Nas páginas finais dos boletins editados entre 1932 e 1935. havia pedidos de intercâmbio para revistas estrangeiras.

${ }^{12}$ Um dos exemplos que podemos citar é o da professora Maria dos Reis Campos, cujo artigo publicado em School and Society e resenhado no v. 1, n.3. no mesmo Boletim em que contribuiu, escrevendo o artigo "A educação primária nos Estados Unidos". Maria dos Reis Campos foi citada por Fernando de Azevedo como um de seus colaboradores na redação do projeto da Reforma. Nessa administração, exerceu o cargo de superintendente do ensino primário. Posteriormente, na administração de Anísio, quando foi criada a Universidade do Distrito Federal, assumiu o cargo de professora chefe da Escola de Educação.

${ }^{13} \mathrm{Na}$ seção de resenhas de artigos, percebemos que as obras citadas foram editadas recentemente. Por exemplo, nov.1, n.1, de janeiro a março de 1930, havia resenhas de artigos publicados em dezembro de 1929. Ov.1,n.2, de abril a junho de 1930, referiuse a publicações de fevereiro do mesmo ano.

${ }^{14}$ Cumpre ressaltar que o primeiro Boletim, editado em 1930, trouxe em sua última página indicação dos dez próximos artigos a publicar. Destes, apenas um não apareceu nas edições posteriores. Os demais compunham os números 2 (cinco dos seis artigos publicados) e 3 (quatro dos seis artigos). O Boletim de número 4 foi concluído com um compêndio que relacionava todos os artigos editados no ano e o conteúdo de todas as demais seções.

${ }^{15}$ Os quatro números da primeira fase podem ser encontrados junto à Biblioteca do Instituto de Estudos Brasileiros(IEB), na USP. Os exemplares da segunda fase estão dispersos em diversas bibliotecas e, apesar de ter recorrido a acervos do Rio de Janeiro e de São Paulo, não logrei reuni-los todos.
} 
vivido, assinados por professores, inspetores escolares, diretores de escolas, administradores da Diretoria Geral, inspetores médicos, enfim, pessoas relacionadas à educação do Rio de Janeiro. Não possuía qualquer título, sendo os artigos dispostos de maneira a apresentar à esquerda da página, em letras maiúsculas, negrito, o nome dos autores; na mesma linha, à direita, os títulos dos trabalhos.

A segunda seção constava de um relato dos acontecimentos da reforma: inaugurações de escolas, conferências, exposições e tudo o mais que tivesse o apoio da Diretoria ${ }^{16}$. "Através das Revistas" resenhava artigos de periódicos nacionais e estrangeiros, especialmente americanos e franceses, mas, também, alemães, austríacos, italianos e russos ${ }^{17}$. "Bibliografia" ocupava-se em informar sobre livros recentemente publicados em português ou outros idiomas ${ }^{18}$.

Os números que compunham a primeira fase foram ilustrados por fotos de construções escolares — clínicas e escolas — e de eventos como a Exposição de Cinematografia Educativa, realizada em 1929 no Distrito Federal, com uma média de 20 ilustrações por periódico; fato que não se repetiu durante a segunda fase.

Substituindo o Boletim de Educação Pública, em 1943, foi criada a Revista de Educação Pública, que perdurou até 1958, tendo sido editados quatorze números.

\section{A Revista Brasileira de Estudos Pedagógicos: primeiros movimentos e direções}

A Revista Brasileira de EstudosPedagógicos ${ }^{19}$ nutre-se ao longo das primeiras décadas de dois movimentos de maior intensidade do que em qualquer outra revista. Um deles, bastante técnico e burocrático, está ligado diretamente ao

\footnotetext{
${ }^{16} \mathrm{Na}$ administração de Anísio Teixeira, esta seção transformou-se em mera compilação de decretos, discursos e relatórios. Especialmente significativo foram os números 5 e 6 do v.3, quando "Factos e iniciativas" assumiu tal importância que substituiu as demais seções. exceto a de artigos, reduzida, entretanto, a 35 páginas.

" Entre as revistas mais citadas estão: Progressive Education, Washington D.C, período de fevereiro de 1930 a março de 1933 (sete artigos); LaNouvelle Éducation, período de março a maio de 1930 (cinco artigos), Revista de Pedagogia, Madrid, período de março a julho de 1930 (cinco artigos) e Bulletin de Information, Moscou, período de março a dezembro de 1929 (quatro artigos).

" Durante a administração de Anísio Teixeira estas duas seç̃es apareceram em ordem invertida no interior do Boletim, vindo "Bibliografia" seguida de "Através das Revistas".

"Publicada pelo Instituto Nacional de Estudos Pedagógicos (INEP), do Ministério da Educação A Revista inicia-se em 1944e, apesar de sair de circulação durante três anos, ainda não apresenta sinais de decadência, tanto que a última publicação data de 1992.
} 
programa do Instituto Nacional de Estudos Pedagógicos, seja no sentido de apurar elementos e material obtidos através das investigações e inquéritos que realiza, seja como um aparelho de enumeração ou registro das instituições e atividades da educação nacional, todos divulgados pela Revista. $\mathrm{O}$ outro movimento é mais teórico, no sentido de que reflete as idéias dos autores da Revista na observação dos fatos educacionais, exame dos princípios e análise de questões de aplicação.

Os movimentos, apesar da sua energia e intensidade, são quase imperceptíveis no interior da Revista, mas se faz possível a captação deles. Do primeiro, pelo exame dos resultados de trabalhos realizados pelos diferentes órgãos do Ministério da Educação, bem como dos dados estatísticos, dos textos da Lei e das decisões administrativas de maior relevância. Também, mediante o que a Revista divulga sobre as normas de orientação pedagógica, principalmente nas seções: "Documentação" e "Através de Revistas e Jornais". Do outro movimento, o "teórico", pode-se recolher o seu sentido na seção "Idéias e Debates", constituída mormente das idéias dos autores que revelam lideranças importantes e que se destacam em textos assinados por grandes educadores brasileiros, e das experiências de outros países a oferecerem princípios gerais da filosofia e da ciência da educação, mediante autores como Durkheim, Dewey, Montessori, Decroh/e Kirschensteiner.

$\mathrm{O}$ aspecto particular da Revista é o da rnanutenção de uma dependência aos propósitos dos seus diretores e de alguns colaboradores, os quais se permitiam destinar os rumos da educação brasileira Por intermédio desses educadores, a Revista firma uma corrente poderosa na organização das práticas e direções da vida escolar brasileira Mas, o que mais chama a atenção é o feto de a Revista incorporar os objetivos colocados pelo Instituto Nacional de Estudos Pedagógicos (INEP) ${ }^{20}$, no sentido de organizar a documentação aluai relativa às técnicas pedagógicas e de manter intercâmbio com instituições do país e do estrangeiro. Aliás, é dito que o INEP lançou em 1944 a Revista Brasileira de Estudos Pedagógicos com a finalidade de divulgar os seus trabalhos.

\footnotetext{
${ }^{20}$ O INEP nasceu como "Instituto Nacional de Pedagogia", e a Lei n ${ }^{\circ} 378$, de 13 de janeiro de 1937, lhe deu origem. Foi instalado no ano seguinte. Gustavo Capanema, ministro da Educação, atentara para a importância desse órgão, vendo-o como um aparelho centrai no pais destinado a inquéritos, estudos, pesquisas e demonstrações. Acreditava Capanema que o INEP, além dos trabalhos sobre problemas educacionais, pudesse sistematizar e divulgar aqueles realizados pelas instituições pedagógicas, públicas e particulares. No Decreto-Lei $n^{\circ}$ 580, de 30 de julho de 1938, aparece a função do INEP de ser um órgão de intercâmbio com outros países, alterando sua denominação para "Instituto Nacional de Estudos Pedagógicos". Capanema faz a "Apresentação" da Revista no seu primeiro número.
} 
O editorial da Revista (v. 10, n.28, maio/jun. 1947) diz que o INEP visa a uma ampla renovação científica do trabalho educativo e que tem utilizado todos os meios possíveis para divulgar os conhecimentos relativos à Ciência Pedagógica. Em seguida, vem o comentário de que o Ensino Normal atravessa uma fase de amplo desenvolvimento, a que o governo federal não está alheio, apesar de que, em diversas unidades federais, várias Escolas Normais não se destinaram ao ensino dos princípios e técnicas da Ciência Pedagógica. O editorial de maio a agosto de 1950 (v. 14, n.39) diz que o INEP procura encarar com objetividade as questões educacionais do Brasil e que, já em 1946, formulara um plano, sendo a primeira tentativa de âmbito nacional para resolver o problema do ensino primário no meio brasileiro ${ }^{21}$. O número seguinte da Revista diz que esse plano, organizado pelo INEP, tem por objetivo levar o auxílio federal às diversas unidades federadas, na proporção de suas necessidades, e que o Sistema das Escolas Normais Rurais, conforme planejou, ou os seus cursos de aperfeiçoamento, vêm representar a concretização do sonho dos educadores em prol de uma educação mais democrática. A Revista está impregnada de intentos do INEP, mostrados pelo registro de suas realizações juntamente com os órgãos executores de planos de trabalho. Neste sentido, o INEP investiu com maior intensidade, provavelmente no ano de 1956. Por outro lado, essas realizações destacam a importância do INEP devido principalmente ao alcance "técnico", isto é, ao aprimoramento de técnicas e métodos, informação pedagógica, documentação (cita-se o registro sistemático das publicações brasileiras sobre educação e o Serviço de Biblioteca, responsável pela seleção e classificação de recortes de jornais e de noticiário de interesse do INEP). Por outro lado, o INEP, atendendo aos seus próprios fins, usa

\footnotetext{
${ }^{21}$ Foram decretadas nesse ano (1946) a Lei Orgânica do Ensino Primário e a Lei Orgânica do Ensino Normal, que procuram dar uma base comum a graus e tipos de ensino, e como adapla-lá às condições regionais e locais.
} 
a Revista ${ }^{22}$ para divulgar aquelas realizações e com isto, se torna um poderoso canal distribuidor de programas educacionais.

Nas primeiras décadas, após o nascimento da Revista, não é difícil determinar os eixos da educação sobre os quais ela se fundamenta. Isto porque são eixos estabelecidos pelo diretor do INEP ${ }^{23}$ e pelos colaboradores da Revista ${ }^{24}$, em especial alguns da Comissão de Redação que têm os seus nomes ligados diretamente às Reformas Nacionais que surgiram a partir de 1930, ou que são daquela geração de educadores enquadrada no movimento de renovação escolar que vinha se desenvolvendo com uma crescente intensidade desde a década de 20.

Uma primeira linha diretiva com vistas à educação pode ser observada no artigo "Contribuição Norte-Americana à Educação no Brasil", de Venâncio Filho \{Revista Brasileira de Estudos Pedagógicos, v.9, n.25, p.229, nov./dez. 1946). O autor diz que o exame desta contribuição já se fizera outras vezes. Assim em 1940, o professor Carneiro Leão realizou uma síntese da história norte-americana por sugestão do Instituto Brasil-Estados Unidos, repetindo Gustavo Lessa que já a fizera em 1935, e outros, como Afrânio Peixoto e Milton Rodrigues. Dentre os trabalhos, destacam-se dois, nos quais o tema se apresenta especificamente: "Aspectos da cultura norte-americana", de Anísio Teixeira, em 1937, e"A educação

\footnotetext{
${ }^{22}$ Não é difícil perceber esse mecanismo. É o caso de se citar alguns exemplos: algumas atividades do INEP. desenvolvidas durante o ano de 1956, foram divulgadas pela Revista. Assim, a estruturação do Centro Brasileiro de Pesquisas Educacionais, na capital da República e dos Centros Regionais, sediados nas capitais dos Estados do Rio Grande do Sul, São Paulo, Minas Gerais, Bahia e Pernambuco, tendo entre outros objetivos a elaboração de planos, recomendações e sugestões para a revisão e reconstrução educacional do país; o acordo entre a Unesco e a Campanha de Aperfeiçoamento do Pessoal de Nível Superior (CAPES) para participar das atividades desse Centro; a assistência financeira dos estados, de acordo com um plano de construção escolares cm 1948, o INEP leria iniciado, decisivamente, seu programa de cooperação financeira para ampliação e melhoria da rede de Escolas Normais - e a assistência técnica, correspondendo ao programa de aperfeiçoamento dos magistérios primário e normal e à CAPES; a aplicação anual da verba de quatro milhões de cruzeiros, por parte do INEP, para a aquisição de livros, revistas e material de uso didático, especialmente destinados a escolas primárias e normais (para melhores informações consultar Revista Brasileira de Estudos Pedagógicos, v.27, n. 65, jan./mar. 1957). Nota importante: com a publicação dos n.59, 60, 61 e 62(jul./ set. 1956), do n.63 (out./dez.) e do n 65 (jan./mar. 1957), foi conseguida a expressiva tiragem de 3000 exemplares

${ }^{2 l}$ Manuel Bergstrõm Lourenço Filho e Anísio Spíndola Teixeira estavam entre os primeiros direlores do INEP e participaram também da Revista como colaboradores. Lourenço Filho foi reformador da Instrução Pública do Ceará (1923), organizador do Instituto de Educação do Distrito Federal (1932); e primeiro diretor do INEP (1938-1952), teve a direção dos trabalhos na Campanha de Educação de Adultos no âmbito do Ministério da Educação (1947-1950) e foi delegado do Brasil na III Conferência da Unesco. Anísio Teixeira foi diretor geral da Instrução Pública da Bahia (1924-1929); diretor geral de Educação do Distrito Federal (1931 -1935); conselheiro para o Ensino Superior da Unesco (1946-1947); secretário da Educação e Saúde do Estado da Bahia (1947-1951). secretário geral da CAPES (1951 -1964). diretor do INEP (1952-1964).

${ }^{24}$ Fez-se a contagem dos nomes dos colaboradores que mais publicaram nos primeiros anos da Revista. Total de artigos: 328 . Colaboradores e número de artigos: Lourenço Filho, 28; Anísio Teixeira, 15; Almeida Júnior, 14; Fernando de Azevedo, 6; F Venâncio Filho, 5; Germano Jardim, 4.
} 
norte-americana", de Lourenço Filho, em 1938. Destes trabalhos, Venâncio destaca os de Anísio Teixeira e Lourenço Filho e sobreleva os seus nomes.

Anísio mostra que a educação nos Estados Unidos, devido às origens de sua formação histórica, tornou-se experimental e democrática, "diferente da européia que é tradicional, empírica e autocrática", e tende a ser cada vez mais cientificamente planejada, processando-se o seu desenvolvimento como se processa o crescimento da natureza (idem, p.231) Venâncio interessa-se por abordar mais de perto o exame da contribuição dos Estados Unidos à educação pelas palavras de Anísio, tanto que as julga como justas e definitivas. Assim diz ele: "pela sua grandeza, pela sua heterogeneidade, pelo próprio vigor do seu desenvolvimento económico, pela estranha celeridade de sua transformação social, pela multiplicidade de origem dos seus cidadãos (...) os Estados Unidos estão apresentando a democracia em luta, com as mais tremendas dificuldades (...) e conduzem esta luta com pacífica firmeza, jovialmente, em liberdade, graças ao aparelho educativo, que lhe constituiu a grande peça nova com que se avantaja sobre as civilizações mais antigas e mais sábias" (Revista Brasileira de Estudos Pedagógicos, v.9, n.25, p.231,nov./dez. 1946).

Lourenço Filho fixou as características da educação norte-americana, sintetizadas em três itens: a magnitude da obra, a unidade político-social e a riqueza e variedade das tendências ${ }^{25}$ e das teorias educacionais. Do exame desta contribuição ${ }^{26}$, Venâncio apresenta pontos essenciais de onde emergem definidas algumas diretrizes para a educação brasileira. Destacam-se aqui: $1^{\circ}$ ) o que é educação de sentido realmente democrático vem do povo para o governo e não deste para aquele, havendo uma participação profunda de toda a sociedade no funcionamento do sistema; $2^{\circ}$ ) a noção de que a escola é peça fundamental do organismo social, de cujo funcionamento depende a nacionalidade.

\footnotetext{
"Em relação às "tendências" da educação brasileira, Lourenço (1938) faz uma análise destas, onde se pode perceber suas diferentes formas e concepções.

${ }^{26}$ Venâncio Filho reproduz as características que já haviam sido fixadas por Lourenço Filho (Revista Brasileira de Estudos Pedagógicos, v.19, n.25, p.231).
} 
Na verdade, idéias de inspiração norte-americana já surgem nos sistemas públicos em 1924, quando o Governo Góes Calmon, na Bahia, chama, para a direção do ensino, Anísio Teixeira, então jovem bacharel em Direito. Depois da viagem que empreende à Europa e aos Estados Unidos, Anísio inicia a renovação do sistema educativo do seu estado. No estudo feito por Venâncio, a ação de maior significação para o progresso do Brasil foi a influência dos "sábios" norte-americanos na formação dos geólogos brasileiros ${ }^{27}$. Sintetizando, Venâncio aponta dois traços da contribuição norte-americana no Brasil: "o sopro renovador dos métodos feito com modéstia e singeleza e o profundo respeito às tradições nacionais" (Revista Brasileira de Estudos Pedagógicos, v.9, n.25, p.264, nov/dez. 1946).

As observações importantes de Venâncio Filho ajudam a perceber o empenho daqueles que compõem o corpo de autores pela sustentação da liderança de um grupo, cujas preocupações pedagógicas para com a educação nacional tornam-se as diretrizes próprias da Revista.

A Revista apresenta, no seu primeiro número (jul. 1944), o artigo de Lourenço Filho, "A Educação, Problema Nacional" numa exposição em que faz valer uma discussão filosófica ${ }^{28}$ e planos específicos de organização educacional ${ }^{29}$. Mais no interior da Revista são colocadas em paralelo as questões pedagógicas e de ensino com aquelas que poderiam ser chamadas de "políticas",

\footnotetext{
${ }^{27}$ Citam-se os engenheiros formados pela Escola de Minas de Ouro Preto, sob a direçâo de Henri Corceix, que tiveram contato com os especialistas que derivaram da viagem de Agassiz, em 1865. Há outras influências norte-americanas a ressaltar: a Biblioteca da Faculdade de Medicina que funciona como laboratório de estudos e de cultura nos moldes norte-americanos. em Belo Horizonte, pela iniciativa do professor Baeta Viana, diplomado nos Estados Unidos. Para a Sociologia Educacional, tem-se a contribuição americana de Delgado de Carvalho. Este professor, por ser conhecedor das coisas norte-americanas e pelo conhecimento da língua, ajudou a Associação Brasileira de Educação na escolha dos beneficiários das dez bolsas oferecidas ao Brasil pelo Instituto de Educação Internacional, a Camegie Endowment, em 1929.

${ }^{28}$ Lourenço Filho propõe o problema da educação nacional nos seus termos mais amplos. Inclui no conceito "educação" o de "nacional". E, na dimensão do "nacional" o de "nação". Isto significa que a educação "não se define, em termos autônomos; deve ser compreendida em função dos demais aspectos da vida coletiva" (Revista Brasileira de Estudos Pedagógicos, n. 1, v. 1, p.7, jul. 1944). Além do mais, a expressão "educação nacional" pode ter o significado de "educação da nação" ou "educação para a nação", embora o conceito seja o mesmo na essência.

${ }^{29}$ Lourenço Filho entende que, nos termos políticos, reconhece-se que a nação tem como finalidade a preservação e a transmissão da cultura. Porém, ele assegura que não basta a "afirmação solene da lei", pois é necessário que lhe suceda "a execução direta, extensa e acabada". E esta envolve questões de organização, de não pequena complexidade. Então, conforme diz. há todo um trabalho de rigorosa definição a se fazer, implicando estudos da mais diversa natureza, no plano político, administrativo, técnico e financeiro. Lourenço cita o Ministério da Educação que, criado em 1930, reorganizado em 1934 e remodelado depois em 1937, tem muito a oferecer como instituição nova. Entende que, uma vez estabelecido o "plano-estatuto", deva-se encarar a forma de execução, com a definição de encargos e responsabilidades, nas várias áreas do poder público.
} 
principalmente referidas a uma política com a finalidade de "estimular a consciência de um processo educativo que tivesse por fim integrar os ideais e as aspirações de todo o povo" (O GRUPO Fluminense na Cultura Nacional apud Lourenço Filho, 1944, p.10). Isto significa que os dois tipos diferentes, o "pedagógico" e o "politico", são examinados na mesma proporção.

Fernando de Azevedo ${ }^{30}$, na conferência "O Nacionalismo e o Universalismo na Cultura" \{Revista Brasileira de Estudos Pedagógicos, v.7, n.21, mar./abr. 1946), pronunciada no Ministério das Relações Exteriores, quando da instalação do Instituto Rio Branco, comenta que: o conjunto dos elementos ou ideais que caracterizam e pelos quais se exprime a mentalidade de cada povo, imprime às diferenças culturais um cunho nacional, distinguindo-as umas das outras. Por isso, aponta as realizadas para a análise do "nacional" na cultura e que devem ser acompanhadas da investigação metódica do "universal". Refere-se ao papel nacional da escola, dizendo que é conhecida a sua utilidade para a prosperidade material ou para a moralidade da nação. Mas o certo é a escola fazer nação, por ser um dos instrumentos mais poderosos de assimilação e de integração cultural e social (Revista Brasileira de Estudos Pedagógicos, v.27, n.65, p.54, jan./mar.1957). Almeida Júnior ${ }^{31}$ diz ser contra a profissionalização da escola primária, esteja esta onde estiver \{Revista Brasileira de Estudos Pedagógicos, v.1, n.1, p.31, 1944), mas que seja "democraticamente, humanamente, uma escola de ensino comum" (idem p.33). Na sua crítica, Almeida diz que cada instituto profissional forma um tipo particular de técnico, enquanto a escola comum visa formar o cidadão. $\mathrm{E}$, se aquelas diversificam e especializam, a

\footnotetext{
${ }^{30}$ Fernando de Azevedo (1958), já em 1933, se definira em atacar e resolver as questões de educação nacional, entre elas as Reformas de São Paulo (1933), quando chamado a um posto de influência e direção. Diz ele: "Foi com os homens dessa geração (...) que se formou, no Brasil, uma consciência educacional, com que o problema da educação, tratado e discutido sob todos os aspectos passou para o primeiro plano das cogitações". Fernando de Azevedo considera a observação de Azevedo Amaral, em 1932, por reconhecer no Manifesto dos Pioneiros "o primeiro pronunciamento de expoentes da cultura nacional no sentido de determinar diretrizes nítidas à solução de um problema, nesse período de necessária renovação da vida brasileira" (Azevedo, 1976, p. 176). ${ }^{31}$ Almeida Júnior tem o seu nome ressaltado com avidez por Fernando de Azevedo: "poucos, mesmo entre os elementos de vanguarda, terão sentido mais profundamente a necessidade de reagir contra uma educação sem relações vitais com as exigências do meio social e com os imperativos e as condições do mundo moderno". Lembra que se moveu dentro do Código de Educação de 1933 quando aí colaborou e que traduzia aspirações comuns à nova corrente do pensamento educacional. Almeida foi diretor geral de ensino em São Paulo (1935-1936), com uma atividade orientada no sentido da nova política educacional, sendo considerado então um dos pioneiros (Azevedo, 1976, p. 183-184).
} 
escola comum unifica e nacionaliza. Por isso, vê a importância da educação primária como "elemento de coesão social e de unidade nacional" (idem, p.34).

Vale, a propósito, colocar que a escola, na década anterior a esta que se está ressaltando, era vista como uma força na obra da reforma social. Assim, o objetivo da Escola Nova era entendido como "um corpo de doutrina com base de aplicação científica, para a consecução de determinados finns na educação (...) princípios necessários na atualidade à boa reflexão filosófica" (Pinto, 1932, p.74): ajustar a escola ao meio, como força de transformação para o aperfeiçoamento da danocracia Ao mesmo tempo, a reforma do ensino deveria ser entendida como uma reorganização radical de todo o aparelho escolar, tendo em vista uma finalidade social (Azevedo, 19-, p.7-23). É, nesse sentido, que a escola toma-se um instrumento fundamental de democratização (Azevedo, 1958).

Sem dúvida, a compreensão do papel que a escola desempenha, a partir dos anos 30, deve ser encontrada na sua inserção no quadro político, econômico e social da época Mas, para essa compreensão, o que importa mais são as questões referentes às Reformas, desde a de 1927, ressaltando-se aquela que está determinada no Código de Educação (1933).

Ainda, faz-se necessário afirmar: aqueles autores que na Revista legitimam valores da cultura, sejam aspectos da cultura brasileira ou norte-americana, estão garantindo a conservação dos privilégios e convicções do grupo de educadores a que pertencem.

O que ocorre na Revista é uma luta do grupo todo para ampliar o espaço da produção cultural e controle da mesma. Este espaço significa não apenas a garantia da existência do grupo, mas o fortalecimento das decisões políticas e sociais. Logo, a Revista centraliza as decisões no âmbito próprio da produção. Fica de todo evidente aquilo que Pierre Bourdieu (1983, p.89) chama de "funcionamento de um campo", que depende dos objetos de disputas, das pessoas com "habitus" prontas a disputarem o jogo, e que o "habitus" lhes permita conhecer as leis dos objetos de disputa, do jogo etc. ${ }^{32}$

\footnotetext{
${ }^{32}$ Bourdieu (1972. p 175) entende "habitus" como um conjunto de esquemas inconscientes, de princípios interiorizados que dão a sua unidade às maneiras de pensar de uma época, qualquer que seja o objeto pensado. Numa definição mais completa. "habtus"é um "sistema de disposições duráveis, estruturas estruturas predispostas a funcionar como estruturas estrururantes, quer dizer,enquanto principio de geração e de estruturação de prática e de representações que podem ser objetivamente' regulares', sem que por isso sejam o produto das obediências a regras, objetivo que não supõe a visão consciente dos fins e o domínio expresso das operações necessárias para atingi-las, e por serem tudo isso, coletivamente orquestradas sem serem o produto da ação combinada de um maestro".
} 
Entendendo o que dizem autores - os que revelam lideranças na educação — no n. 19, v.7, de janeiro de 1946, da Revista, torna-se possível tocar na questão acerca "do que vai por um campo". Em primeiro lugar, constata-se que os autores se utilizam de seus "habitus" para salvaguardam o conceito de educação dado por eles mesmos, os quais constituem o "grupo de educadores". Educação aparece aí como um processo social ligado às condições de vida política, às realidades econômicas e da estrutura moral e religiosa do país. Nesse n. 19, o Editorial tem por tema: "Programa de Educação Nacional" e se define por duas idèias que estão contidas no documento de Eurico Gaspar Dutra - o Programa de Governo - e que são reproduzidas pela Revista. Assim, a primeira contém a afirmação de princípios de ordem político-social com orientação doutrinária e a segunda, na qual se abordam os grandes problemas do ensino brasileiro, com indicações diretivas de solução. Na seção "Idéias e Debates", o artigo de Eurico Gaspar Dutra, "O problema da educação nacional" \{Revista Brasileira de Estudos Pedagógicos, v.7, n. 19, p.5, jan. 1946) e os de alguns outros, penetram fundo no mesmo sentido dado pelo Editorial. Também aparecem conceitos e expressões que, em seu conjunto, contêm elementos de natureza doutrinária - ideais, princípios, valores —, constituindo diretrizes orientadoras de uma educação nacional. É o caso de se citar: educação e democracia, educação e trabalho, ajustamento social, consciência pública, elaboração de cultura, preservação e transmissão da cultura.

Nas colocações acima, nota-se que os autores nos seus artigos têm propósitos fundamentais em comum, e isto lhes garante pertencer a um "grupo" no qual se pressupõe haver um acordo até nos dizeres e ações antagônicas. O campo aí está e é um jogo. Os jogadores participam do jogo, distinguindo-se cada um, mas todos distinguindo-se daqueles que estão fora do campo.

É interessante notar "os que estão 'fora' do campo". São todas as pessoas estranhas ao grupo, isto é, aquelas que não conhecem os mecanismos do campo, pois não são dotadas do "habitus" que lhes 
permitiria isto. Elas não conhecem, também, as leis próprias do jogo e não se servem dos pressupostos que são aceitos pelo grupo.

Na verdade, o campo é um espaço estruturado de posições e se define à medida em que também se definem os objetos de disputa e os interesses específicos dos de "dentro". Quer-se acentuar que tais interesses não se reduzem aos interesses próprios de outros campos. Até mesmo os antagonismos e incoerências postas em relevo, no interior do campo, chegam a ser reproduzidas por qualquer pessoa. É nesse sentido que vem ganhar proporção no "grupo" dos autores da Revista a pergunta de Lourenço Filho (1944, p.9): "desde quando se poderá admitir a existência de uma educação nacional em nosso país?...". Para Lourenço Filho, "educação nacional" pode significar a "Educação da Nação" ou a "Educação para a Nação" e nela vê, naquele momento, "um sentido e uma força que ainda há poucos anos não lograram despertar ou transmitir" (idem, p.27). Tal força será tanto maior se dirigida no sentido de elevação do padrão de vida geral do país, bem como no de tornar a educação "prática e realista, condicionada ao programa de reconstrução econômica, em pleno desenvolvimento" (idem, ibidem). Nas décadas de 40 e 50, este questionamento de Lourenço Filho junto à Revista, influiu nos artigos dos autores, na forma de propósitos para uma educação política no Brasil. Fernando de Azevedo trabalha com o conceito de "cultura", examinandoo no aspecto antropológico, donde entende que a cultura está sempre marcada pelo caráter de cada povo, que é uma função de sua história, de suas tradições e de seus ideais, ao mostrar que o "sentido nacional" do brasileiro, derivado da formação secular do povo à base de uma miscigenação de raças e de culturas, constitui "um sistema de garantias contra a irrupção e a preponderância do nacionalismo exagerado sobre as tradições tendenciais universalistas" (Azevedo, 1946, p.438).

Azevedo (1955, p.3) fala da "unidade nacional" que se foi constituindo progressivamente através do contato com as raças e culturas aborígenes e africanas, mas que teve as suas origens na herança histórico-cultural portuguesa. Diz ele que apesar dessa profunda e enraizada base não há "um 
só Brasil, mas, dentro dele, muitos brasis diferentes num só Brasil nem sempre verdadeiro". Então, nesse caso, segundo ele, é preciso ter uma compreensão do Brasil, tendo em vista a diversidade de áreas geográficas, econômicas e histórico-culturais nos seus diversos aspectos, seja económico, étnico, histórico ou cultural, sendo que cada uma delas corresponde a "um estádio histórico diferente" ${ }^{\prime 33}$. Fica sublinhada a importância de um estudo das áreas culturais mediante a aplicação de métodos e conceitos distintos do ponto de vista histórico, económico ou sociológico para a orientação de técnicas de ação social e política, tanto no plano nacional como nas áreas estudadas. Anísio Teixeira, por sua vez, já divulgara em 1953, na Revista — v. 19, n.49, p.7, à época em que era diretor do INEP — que no Brasil se defrontavam duas mentalidades: de um lado, os que não acreditavam no Brasil, vendo-o como uma nação de terceira ordem que jamais resolveria, pelos seus próprios meios, os seus problemas básicos, e, de outro, aqueles que o julgavam uma nação capaz de se constituir e se mostrar tão rica e própria à civilização quanto os melhores trechos temperados do globo. Diante das colocações de Anísio, pode-se perceber que ele estaria enquadrado naquela segunda mentalidade. Entre outros, o trecho a seguir evidencia isso: "somente agora, a bem dizer, começamos a ser uma nação com suas diversas camadas sociais já se incorporando em um todo, que é e breve ainda mais amplamente será o povo brasileiro considerado ele, todo ele, como a própria nação e não como parcela desdenhada e obscura, sobre que reinava uma diminuta classe dominante" (Teixeira, 1953, p.41. Grifo nosso). Para atender a esta direção das coisas, Anísio apresenta como proposta a criação de condições necessárias a uma ampla experimentação social, mediante uma legislação com a finalidade de dar os poderes e faculdades de organização ${ }^{34}$, do que a de organizar a educação nacional, tal como coisa pré-fabricada e imposta. Procedendo desta maneira, segundo Anísio (1953, p.42), se teria "cumprido o disposto na Constituição

\footnotetext{
${ }^{\mathrm{n}}$ Conforme declara Fernando de Azevedo a expressão "um estádio histórico diferente" é de Pedro Calmon (cf. Revista Brasileira de Estudos Pedagógicos, v.24, n.60, p. 12, out./dez. 1955)

34 A "organização" de que Anísio fala é a da "adaptação de nossas instituições à realidade nacional, para que elas não sejam fictícias nem inadequadas, mas os instrumentos eficazes da solução de nossos realíssimos problemas" (Teixeira, 1953, p.24).
} 
que declara livre a educação, dentro das diretrizes e bases que cumpre ao Governo Federal fixar, com a plasticidade e flexibilidade indispensáveis a que a escala Brasileira (...) brote e cresça da terra, das condições e da experiência brasileira". Diz mais: "Temos que reconstruir a escola brasileira para novas, instantes e mais altas necessidades nacionais..." (idem, ibidem).

Gilberto Freyre, em 1955, esteve às voltas com a questão da história nacional de nosso país, preocupando-se com o problema rural de ensino. Via a "rurbanização" do ensino necessária ao BrasiL, isto é, capaz de dar ao ensino nacional, regional ou estadual, o seu verdadeiro sentido. Na conferência, por ocasião da instalação do Curso de Treinamento de Professores Rurais, em Pernambuco (1955), Glberto Freyre diz do empenho às causas rurais, seja na valorização dos homens como das coisas, sem contudo deixar os valores urbanos. De certo modo, ele via com a formação e o desenvolvimento da mentalidade "rurbana", "uma nova política no Brasil" (Freire, 1956, p.65). Neste sentido, a sugestão de Gilberto Freyre, mais concreta e ampla, é a de projetar "centros transmunicipais de cultura, assistência e recreação que dariam vida intelectualmente nova ao interior do Brasil" (idem, p.71). Expõe, então, na Revista, uma listagem de nomes os quais dariam às populações rurais um contato direto e vivo com a inteligência, o saber e a arte do país. Assim cita Villa-Lobos ${ }^{35}$, "ele próprio e não apenas escutá-lo em disco e vê-lo no cinema", Manoel de Abreu, Manoel Bandeira, José Lins do Rego, Jorge Amado, Procópio Ferreira, César Lattes, Lúcio Costa, Carlos Drummond de Andrade, Raquel de Queirós, Carolina Nabuco, Gilberto Amado, Sérgio Cardoso, Cândido Portinari, Péricles, Silva Melo, Gastão Cruls, Vão Gogo, Fernando de Azevedo ${ }^{36}$, Afonso Arinos, Carlos Estêvão, Pontes de Miranda, Luís Jardim, Álvaro Lins, Anísio Teixeira e Delgado de Carvalho.

\footnotetext{
${ }^{35}$ Villa-Lobos, nas décadas de 30, 40 e em parte, na de 50, no Rio de Janeiro, na época do apogeu da ditadura instaurada por Getúlio Vargas, tem uma ligação com a educação brasileira O INEP premiou e editou trabalhos sobre grandes mestres da educação nacional. Aí estava o nome de Heitor Villa-Lobos entre outros como Anísio Teixeira, Fernando de Azevedo, Firmino Costa Pereira, José Veríssimo e Francisco Rangel Pestana. Com a música, Villa-Lobos aplicou seu plano de educação social através da arte, mas devido ao patrocínio dado pelo governo, foi seriamente criticado por Gilberto Freyre, como por Érico Veríssimo, Manoel Bandeira, Mário de Andrade.

${ }^{6}$ Fernando de Azevedo teria ressaltado na Revista - n. 60, v 24, outubro-dezembro, 1955 - que nos últimos cinquenta anos e, mais particularmente, no segundo quartel deste século, houve no Brasil uma reação contra a "mentalidade retórica", através de um dos movimentos mais fecundos para o conhecimento do Brasil Constaram deste movimento, segundo Azevedo, as coleções de estudos brasileiros que se seguiram à "Brasiliana" — biblioteca de estudos brasileiros fundada pelo próprio Fernando de Azevedo — como "Documentos Brasileiros", fundada em 1936 por Gilberto Freyre; a "Biblioteca Histórica Brasileira", iniciada em 1940, sob a direção de Rubens Borba de Morais; a "Biblioteca Histórica Paulista", em 1952, sob a orientação de Afonso Taunay.
} 
Por tudo isto, pode-se dizer que, na Revista, se reconhecem nomes ocupando diferentes posições nos domínios da literatura, da política, da sociologia, da pedagogia, mas quaisquer que sejam, todos eles estão constituindo o campo da Educação. Também é certo, como já foi dito em uma outra análise de periódico: "As produções vinculadas pelo periódico traduzem os anseios organizadores típicos da administração ao mesmo tempo que expressam o ponto de vista de produtores do conhecimento..." (Catani, 1989, p. 115).

Aproximo esta última citação à conclusão a que se chega: nos primeiros anos de vida da Revista Brasileira de Estudos Pedagógicos, os editoriais e artigos tanto traduzem o que os diretores do INEP e o seu grupo de ligação planejam associados ao Ministério da Educação, como expressam os pontos de vista destes sobre "educação". Daí, poder-se pressupor que tais produtores da educação são os maiores responsáveis pela organização do campo educacional. Eles usam a Revista para fazer valer suas realizações e a divulgação de ideais. Nada mais claro que: os primeiros movimentos e direções da Revista tenham sido para o predomínio de uma "educação nacional" a ser situada no conjunto do plano da cultura. Sobre essa educação levantam-se algumas questões: O que é a "educação nacional"? Nas condições brasileiras, a educação pode ser um elemento de "unidade nacional"? O que se fala na Revista a respeito de uma política nacional de educação?

\section{Referências Bibliográficas}

AZEVEDO, Fernando de. A escola nova e a reforma. Boletim de Educação Pública, Rio de Janeiro, n.1, p.7-23, [19--].

. O nacionalismo e o universalismo na cultura. Revista Brasileira de Estudos Pedagógicos, Rio de Janeiro, v.7, n.21, mar./abr. 1946.

. Para a análise e interpretação do Brasil. Revista Brasileira de Estudos Pedagógicos, Rio de Janeiro, v.24, n.60, out./dez. 1955. 
. A educação entre dois mundos: problemas, perspectivas e orientações. São Paulo: Melhoramentos, 1958. (Obras completas, 6).

. Novos caminhos, novos fins: a nova política de educação no Brasil; subsídios para uma história de quatro anos. São Paulo: Melhoramentos, 1969. (Obras completas, 7).

. A cultura brasi'eira.5.ed. São Paulo: Melhoramentos, 1976. parte 3:A transmissão da cultura.

BOLETIM DE EDUCAÇÃO PÚBLICA. Rio de Janeiro: Diretoria Geral de Instrução Pública do Distrito Federal, v.1-5, n.1-14, 1930-1935.

BOURDIEU, Pierre. Esquisse d'une theórie de la pratique. Génève: Droz, 1972.

. Questões de sociologia. Rio de Janeiro: Marco Zero, 1983. p.89: Algumas propriedades dos campos.

CATANI, Denice Bárbara. Educadores à meia-luz: um estudo sobre a Revista de Ensino da Associação Beneficente do Professorado Público de São Paulo: 19021918. São Paulo, 1989. Tese (Doutorado) — Faculdade de Educação da USP.

FREYRE, Gilberto. Sugestões para uma nova política no Brasil: a rurbana. Revista Brasileira de Estudos Pedagógicos, Rio de Janeiro, v.27, n.65,jan./mar. 1956.

LEMME, Paschoal. Memórias: vida de família, formação profissional, opção política. São Paulo: Cortez: INEP, 1988.

LOURENÇO FILHO, MB. Tendências da educação brasileira. São Paulo: Melhoramentos, 1938. 158p. (Biblioteca de educação, 29).

. A educação, problema nacional. Revista Brasileira de Estudos Pedagógicos, Rio de Janeiro, n.1,v.1, p.7-28, jul. 1944.

PINTO, Estevão. A escola e a formação da mentalidade popular do Brasil. São Paulo: Melhoramentos, 1932. (Biblioteca de Educação, 16).

REVISTA BRASILEIRA DE ESTUDOS PEDAGÓGICOS. Rio de Janeiro: Instituto Nacional de Estudos Pedagógicos, v. 1, n. 1, jul. 1944 ao v.51, n.93, jan/mar. 1964. 
SILVEIRA, Alfredo B. da. História do Instituto de Educação. Rio de Janeiro: [s.n.], 1954.

TEIXEIRA, Anísio. Condições para a reconstrução educacional brasileira. Revista Brasileira de Estudos Pedagógicos, Rio de Janeiro, v. 19, n.49, jan./mar. 1953.

- A crise educacional brasileira. Revista Brasileira de Estudos Pedagógicos, Rio de Janeiro, v.19, n.50, abr.jun. 1953.

Recebido em 10 de março de 1993

Diana Gonçalves Vidal, doutoranda em História e Filosofia da Educação pela Faculdade de Educação da Universidade de São Paulo (USP), é professora de Educação Brasileira e História da Educação na Faculdade de Pedagogia das Faculdades "Padre Anchieta", Jundiaí, SP.

Marilena Aparecida Jorge Guedes de Camargo, doutoranda em História e Filosofia da Educação pela Faculdade de Educação da Universidade de São Paulo (USP), é professora Assistente do Departamento de Educação do Instituto de Biociências da UNESP — Rio Claro, SP.

This article is about two studies ofspecialized Education reviews-Boletim de Educação Pública and Revista Brasileira de Estudos Pedagógicos—in the hope that, since afirst contact with those magazines, may help the searcher in History of Brazilian Education giving him data for his work. In analysis of Boletim de Educação Pública stand out the informaíions systematized about the life cycle setting the review in its historical moment andwanting to notice the review inPoliticalinjunctionswhich definedlheir origin. Respecting Revista Brasileira de Estudos Pedagógicos, thefocus occured about two movements —one technical and bureaucratic, dose related with INEP'sprogramme; and 
other, theoretical, refleeting the authors 'ideas, the observation ofEducational events, examination of principies and analysis qfaplication questions.

II s 'agit de deux études de revues spécialisées en Éducation-Boletim de Educação Pública et Revista Brasileira de Estudos Pedagógicos - avec l'expectative de que le contact initial avec ces revues aide lenquèteur dons l'Histoire de l 'Éducation Brésilienne, en lui donnant des Índices à son travail. Dans l'analyse du Boletim de Educação Pública, on a privilegie la systématisation des informations sur le cycle de vie, en situant la revue dans son moment historique et en tâchant de comprendre la publication dans les injonctions politiques que lui ont donné l 'origine. A l'égardde la Revista Brasileira de Estudos Pedagógicos, le thème se rapporte à deux mouvements; l'un, technique et bureaucrate, directement lié auprogramme de l'INEP; et l'autre, théorique.queréjléchitlesidéesdesauteursdalarevue, l'observation des faits éducatifs, l'examen des príncipes et l'analyse des questions d'application.

El artículo trata de los estúdios de revistas especializadas en educación - Revista Brasileira de Estudos Pedagógicos y Boletim de Educação Pública -, en la espectaíiva que el contacto inicial con estos periódicos auxilie ai pesquisador en Hisloria de la Educación Brasileha dandole índices para su trabajo. En el análisis dei Boletim da Educação Pública se dio prioridada lasistematizaciónde informaciones sobre el ciclo de vida, situando la revista en su momento históricoy tentanto encuadrar lapublicación dentro de las conjunciones políticas que le dieron origen. Con respecto a la Revista Brasileira de Estudos Pedagógicos, el enfoque incidia sobre dos movimientos: uno, técnico y burocrático, ligado diretamente ai programa dei INEP; y oiro, teórico, reflejando las ideas de los autores de la revista, la observación de los hechos educacionales, examen de los princípios y análisis de las cuestiones de aplicación. 